\title{
Bodies without names: A retrospective review of unidentified decedents at Salt River Mortuary, Cape Town, South Africa, 2010 - 2017
}

\author{
K M Reid, BSc, BMed (Sc) Hons, MSc (Med); L J Martin, MB ChB, Dip For Med (SA), MMed (Forensic Pathology), FC For Path (SA); \\ L J Heathfield, BSc, BSc (Med) Hons, PgDip Health Professions Education, MSc (Forensic Science), PhD
}

Division of Forensic Medicine and Toxicology, Department of Pathology, Faculty of Health Sciences, University of Cape Town, South Africa

Corresponding author: L J Heathfield (laura.heathfield@uct.ac.za)

\begin{abstract}
Background. Decedents who remain unidentified and/or unclaimed following postmortem investigations are an international occurrence. Salt River Mortuary (SRM), one of the largest and busiest mortuaries in Cape Town, South Africa, also experiences this burden; however, little is known about the nature of these cases.

Objectives. To review all cases admitted to SRM between 1 January 2010 and 31 December 2017 ( $n=26960$ ), with the objectives of quantifying the number of decedents who remained unidentified, and to better understand circumstances surrounding death and the identification methods that were attempted.

Methods. Data pertaining to unidentified cases were collected from mortuary burial records and medicolegal case files. Data were analysed using Microsoft Excel 2013 (Microsoft, USA).

Results. Over the 8-year period, 2476 cases (mean 9.2\% of caseload per annum) admitted to SRM remained unidentified. Bodies underwent an autopsy after a median of 3 days after a death declaration. However, in cases of decomposition, skeletonisation or other physical inhibitors of visual identification $(n=345 ; 14.1 \%)$, the time between death and autopsy was undetermined owing to the overall lack of entomology analyses. Approximately $56.9 \%$ ( $n=1408)$ of cases were between 20 and 50 years of age, and were predominantly males (78.7\%). Unnatural injury-related deaths accounted for $32.4 \%$ of unidentified deaths, with firearms, assault and stabbings contributing approximately one-third each. With regard to identification attempts, forensic anthropology was requested in only $1.5 \%$ of these cases, and DNA analysis appeared to be used in only $23.6 \%$ of cases. Data pertaining to secondary identifiers, forensic odontology and fingerprint analyses were not formally recorded.

Conclusions. The relatively short time interval between death declaration and postmortem examination suggests that DNA analysis should be more regularly utilised. Furthermore, it is urged that other ancillary investigations should be more regularly employed; that there is a greater collaboration between stakeholders and identification attempts; and that results are centrally recorded.
\end{abstract}

S Afr Med J 2020;110(3):223-228. https://doi.org/10.7196/SAMJ.2020.v110i3.14192

The burden of unidentified bodies is a problem faced internationally, and numerous retrospective reviews have been conducted on this topic. These have focused on understanding variables surrounding the cause of death, demographic profiles of the decedents and possible causes. $^{[1-6]}$ The extent of the burden differs between countries, and is often correlated with the socioeconomic standing of countries, with developing countries experiencing greater numbers of unidentified bodies per year, ${ }^{[3-5]}$ as opposed to developed countries, such as the $\mathrm{USA}^{[6]}$ and those in Europe. ${ }^{[1,2]}$

While one study has been conducted in South Africa (SA) regarding this topic, it was exclusive to the Pretoria Medico-Legal Laboratory. ${ }^{[3]}$ Besides this study, there is very little information pertaining to unidentified bodies in SA. In the Western Cape Province alone, there are 16 forensic pathology service centres. Salt River Mortuary (SRM) is one of the two M6 mortuaries in the Western Cape, i.e. it is affiliated to a tertiary academic centre, and receives among the most admissions in the province (M6 is defined as a caseload of $>2000$ per annum). SRM services the western metropole of the City of Cape Town, which has a catchment population of $\sim 3.7$ million. ${ }^{[7,8]}$

In $\mathrm{SA}$, when a deceased person is found and an unnatural cause of death is suspected, a medicolegal investigation is undertaken to determine the cause of death. ${ }^{[9]}$ Cases referred for autopsies are governed by legislation ${ }^{[10-12]}$ and include procedural-related deaths; sudden, unexpected deaths; and cases involving the omission or commission of an act or the involvement of an external force. ${ }^{[12]}$ In addition to determining the cause of death, deceased individuals need to be identified. The identification process falls within the mandate of the South African Police Service (SAPS), which is assisted by the Forensic Pathology Service (FPS). ${ }^{[1]]}$

Identification is primarily performed through visual confirmation by the next-of-kin or a legal guardian. Secondary identifiers, such as tattoos and scars, can also give leads for the positive identification of individuals. ${ }^{[13]}$ However, in circumstances of significant physical trauma (e.g. burns, decomposition), alternative scientific means of identification, such as fingerprints, ${ }^{[14]}$ DNA testing, ${ }^{[15,16]}$ odontology analyses, ${ }^{[17,18]}$ and/or anthropometric analyses, ${ }^{[19,20]}$ are recommended. If a body is not identified within 7 days of death, SRM follows the procedure that fingerprints and biological samples for DNA testing should be obtained. These samples are typically collected after the autopsy by specifically trained SAPS personnel, following communication and arrangement with management at the forensic facility, who are ultimately the custodians of the body. ${ }^{[1]}$

Furthermore, SA legislation dictates that should a decedent not be identified within 30 days after death, the body becomes the responsibility of the state. ${ }^{[10]}$ Thereafter, the state is responsible 
for the arrangement of a pauper burial of the decedent; however, this can often take months or years. Should the decedent be identified in the period after becoming the state's responsibility, the family can either opt to proceed with the pauper burial (on the basis of financial constraints) or make their own internment arrangements.

\section{Objectives}

Empirical data pertaining to unidentified remains in Cape Town are not readily available; hence, a retrospective review was undertaken at SRM with the aim of determining the number and demographics of cases that remained unidentified, as well as describing the circumstances surrounding the death and various elements of identification. Understanding the factors with regard to the identification process and the types of cases that remain unidentified, may aid in the development of better processes to identify individuals in the future. This has important implications, not only for the state, but also for families who need closure and social justice.

\section{Methods}

The selection of relevant cases was performed using SRM records regarding 'state-pauper' burials from 2010 to 2017. All cases with no confirmed identification at the time of state-pauper burial were included. In this study, 'unidentified' was defined according to the regulations regarding the rendering of forensic pathology services, ${ }^{[11]}$ whereby individuals who have not been identified within 7 days are classified as unidentified, and therefore require scientific identification. Because of the cross-sectional nature of this research, there is a possibility that a few of the more recent cases included in this study may have subsequently been identified after data collection.

The internal Office Autopsy Database was then consulted to obtain information pertaining to these cases regarding their demographics (e.g. age, sex), circumstances surrounding death, postmortem investigation (including attempts at identification), as well as cause of death. Information on the Office Autopsy Database was originally gathered from the hard-copy medicolegal case files, which include a postmortem report, death scene documentation and other documentation relevant to the case.

The 'age of decedent' variable was captured as per the forensic pathologists' interpretation at the time of autopsy, which was largely subjective, but also influenced by external features and characteristics (e.g. tooth eruption, phenotype, clothing). These ages were therefore classified into broader categories for the purpose of this study: non-viable fetuses and stillbirths, neonates ( $\leq 14$ days of age), 15 - 365 days, 1 - 9 years, $10-19$ years, 20 - 29 years, 30 - 39 years, $40-49$ years, 50 - 59 years, $\geq 60$ years, not recorded and unknown. It is acknowledged that these age groupings are not necessarily anthropologically accurate; ${ }^{[21]}$ however, anthropological age estimation was not routinely performed.

Additional information regarding the postmortem interval (time since death and discovery of remains, as estimated by entomology), as well as anthropological analyses, was obtained through consultation with local specialists. Notes on clothing and other secondary identifying features were searched for in the medicolegal case files. All variables for analysis were collated in Microsoft Excel 13 (Microsoft, USA) for the performance of descriptive statistics.

While the deceased individual's race was noted at the time of autopsy on the medicolegal reports, it was not included as a variable owing to its subjectivity and its sensitivity in research.

\section{Ethical approval}

Ethical approval to conduct this study was obtained from the Human Research Ethics Committee, Faculty of Health Sciences, University of Cape Town (ref. no. HREC 342/2016). The internal Office Autopsy Database is an ethically registered database (ref. no. HREC R036/2014).

\section{Results \\ Overview of burden and demo- graphics of cases}

The total caseload experienced at SRM over the study period ranged between 2904 and 3886 cases per annum, and an overall increase was documented after 8 years (Fig. 1). A total of 2476 of 27060 cases (9.2\%) were determined to be unidentified from the data reviewed (Fig. 1). Of the individuals who were unidentified, the time that elapsed between the date of death declaration and date of the postmortem procedure ranged from 0 to 33 (mean 3.80) days (where data were available). In 2017, the median was determined to be 5.94 days, while every other year the median was $\sim 3.5(3.20$ - 3.93) days.

The majority of individuals who remained unidentified were males ( $n=1954 ; 78.7 \%$ ), with some cases $(n=88 ; 3.7 \%)$ having an

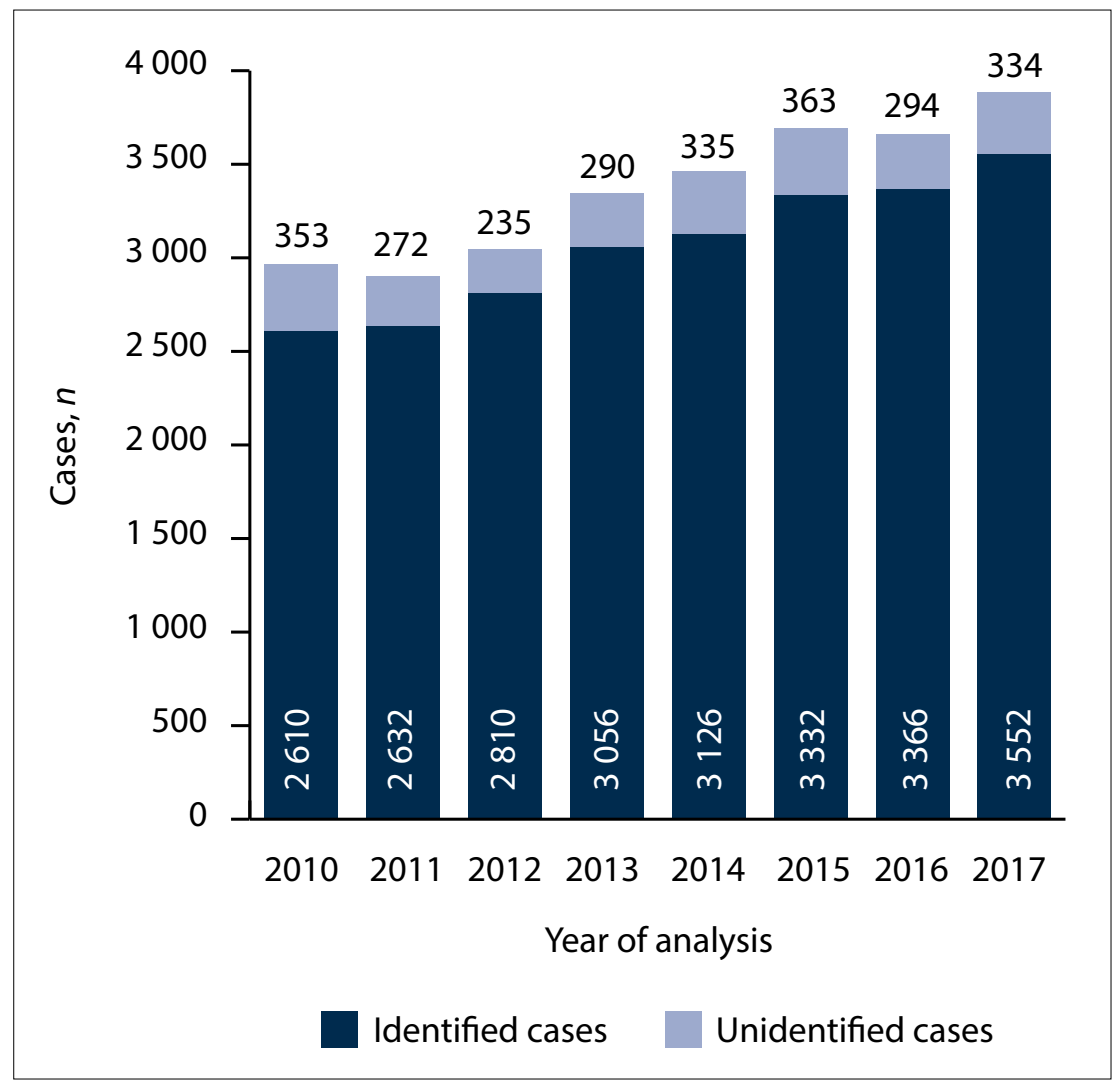

Fig. 1. Total caseload observed at Salt River Mortuary (SRM) and the number of unidentified decedents across the 8-year review period (2010 - 2017). The bars indicate the total number of cases admitted to SRM in a specific year. 
undetermined sex because of the gestational age of the fetus or physical damage to the body. Almost half ( $n=1148 ; 46.4 \%)$ of the cases were in the combined age groups of 20 - 39 years, with the third highest category $(n=266 ; 10.74 \%)$ being the 'non-viable fetuses and stillbirths' age category (Fig. 2).

\section{Admission circumstances and cause of death}

Deaths investigated at SRM with an alleged 'unnatural' cause were the most dominant category among unidentified individuals ( $n=802 ; 32.4 \%)$. Of these, the most prevalent methods of death were assaults ( $n=242 ; 30.2 \%)$, stabbings ( $n=223 ; 27.8 \%)$ and gunshots $(n=220$; $27.4 \%$ ). In cases of alleged homicide, it was determined that the average age of victims was 29 years, and $91.9 \%$ of decedents were males. Natural causes of death accounted for $18.0 \%$ $(n=445)$ and suicides for $2.4 \%(n=59)$, while $\sim 5.4 \%$ ( $n=134)$ of cases were deemed to have accidental causes of death. Other cases were still under postmortem investigation or had not been concluded in court; hence, it was unclear what the 'manner of death' category was.

Of the cases included in this study, $14.1 \%$ $(n=345)$ were physically unidentifiable by their next-of-kin owing to decomposition $(n=134 ; 5.5 \%)$, burns $(n=109 ; 4.4 \%)$, skeletonisation $(n=41 ; 1.6 \%)$ and other means $(n=61 ; 2.5 \%)$, such as scavenging and dismemberment, or a combination of the abovementioned means. In these physically unidentifiable cases, $44(12.8 \%)$ were recovered from aquatic environments, such as the ocean, lakes and rivers.

\section{Attempts at identification}

Radiological examination with the Lodox Xmplar-dr (Lodox Systems, SA) was performed on all cases admitted to SRM; however, it was not clear whether these scans assisted in identification of any individuals. While physical secondary identifiers (e.g. clothing, tattoos, scars, piercing) were recorded in the contemporaneous notes of several cases, these were inconsistent and data were not collated, transferred or centrally stored. It was unclear whether SAPS knew about these data and if the data assisted in identification.

While it is standard procedure for SAPS to collect fingerprints from all individuals not identified after 7 days of death, there was no record of the cases for which

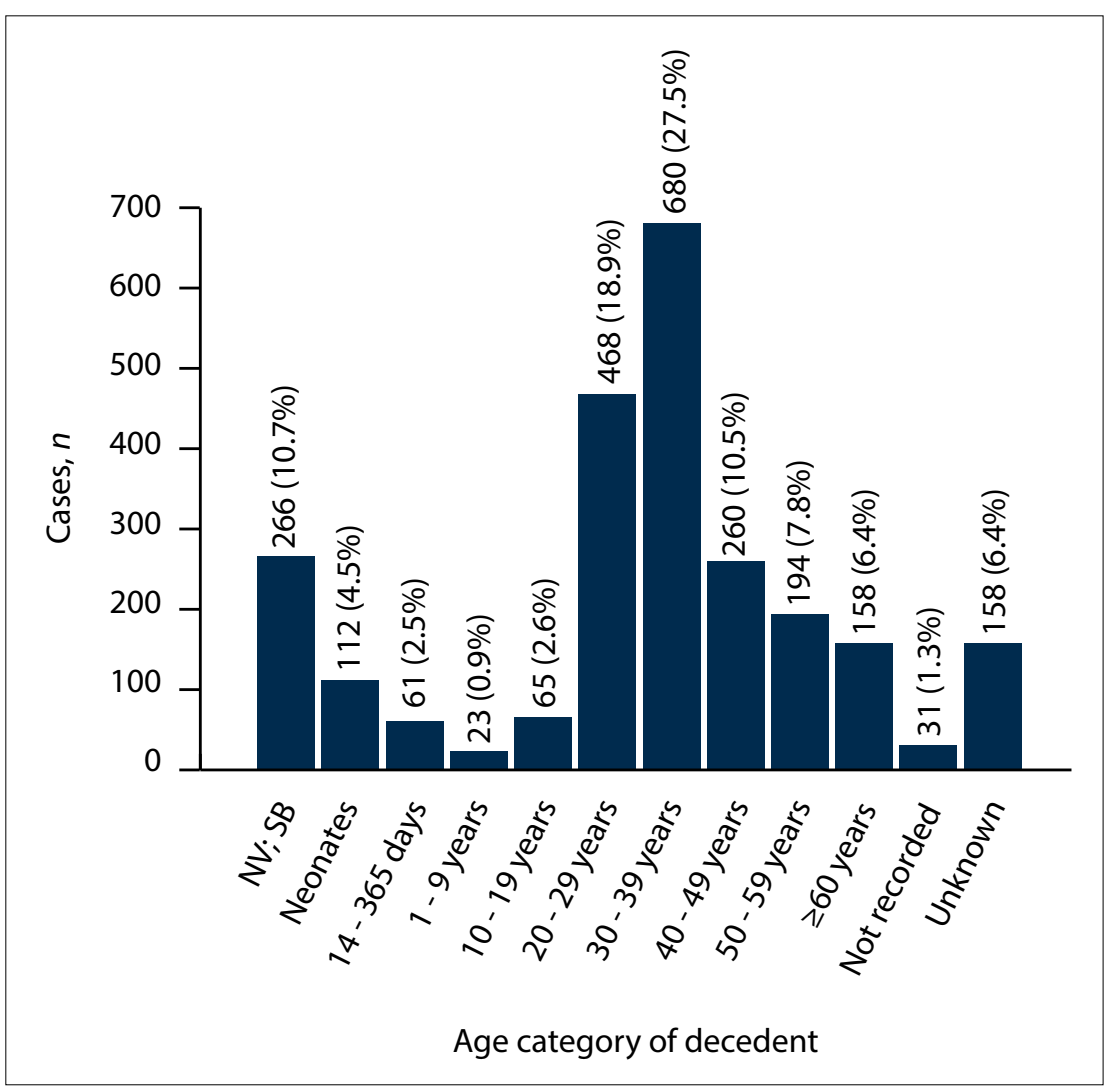

Fig. 2. Distribution of unidentified cases at Salt River Mortuary from 2010 to 2017 according to age category of decedent. Almost half (46\%) of the unidentified person cases fell between the ages of 20 and 40 years, followed by the category of 'non-viable fetus and stillbirths'. Neonates were defined as babies born alive (live births), who died within 14 days of birth. (NV=non-viable fetus; SB = stillbirth.) fingerprints were collected, despite efforts to obtain this information. Anthropological analyses were done in $36(1.5 \%)$ cases, while it appeared that no cases were referred for forensic odontology. Determination of the postmortem interval (PMI) was requested via entomological analysis in only 4 of the 2476 cases $(0.2 \%)$. However, in all 4 cases PMI estimation could only be made with sufficient accuracy and reliability in terms of season of year.

Across the 8 years of review, biological samples for DNA analysis were collected by the forensic pathologist in 582 of the 2467 (23.5\%) cases. The most commonly obtained sample type was blood (collected into an ethylenediaminetetra-acetic acid (EDTA) vacutainer) ( $n=485 ; 91.8 \%)$, followed by tissue specimens $(n=84 ; 15.9 \%)$ (Fig. 3). In a small proportion of cases, both blood and soft tissue $(n=7 ; 1.2 \%)$ or bone $(n=6$; $1.0 \%$ ) was obtained. Unfortunately, there was no record of whether SAPS personnel had collected additional swabs or other biological samples (e.g. nail clippings) after the autopsy, despite extensive efforts to request this information.

\section{Discussion}

The percentage of cases remaining unidentified at SRM was 9.2 (range 7.7 11.9\%; total caseload, $n=2904-3886)$ per annum (Fig. 1). This was similar to that at the Pretoria Medico-Legal Laboratory, which reported an average of $9 \%$ (range 7 $10 \%$; total caseload, $n=2253-2461)$ per annum. ${ }^{[3]}$ The percentage of unidentified bodies observed at SRM was more than 2 -fold higher than that at a forensic facility in the city of Chandigarh, India $(n=123$; $3.9 \%$ over a 5 -year period) ${ }^{[4]}$ but less than that observed at the Calcutta Police Morgue, India ( $n=505 ; 20.1 \%$ over a 2 -year period). ${ }^{[5]}$ When compared with a study in the USA, the number of unidentified individuals per year at SRM $(n=310)$ was similar to the national number in the USA $(n=413$ per annum; $n=10748$ over 26 years). ${ }^{[6]}$

The variations observed in the number of unidentified persons across different countries and regions of countries can be attributed to various factors. The most likely and well-described factor is the socioeconomic standing of the citizens of a country. Developing countries and poor regions within a country are burdened by less-fortunate individuals, and homelessness is likely. ${ }^{[5,6]}$ In 2019, it was estimated that there were $\sim 1.1 \%$ ( $n=4862$ ) homeless people in the greater Cape Town area, with $47 \%$ of the population in the Cape Town metropole 


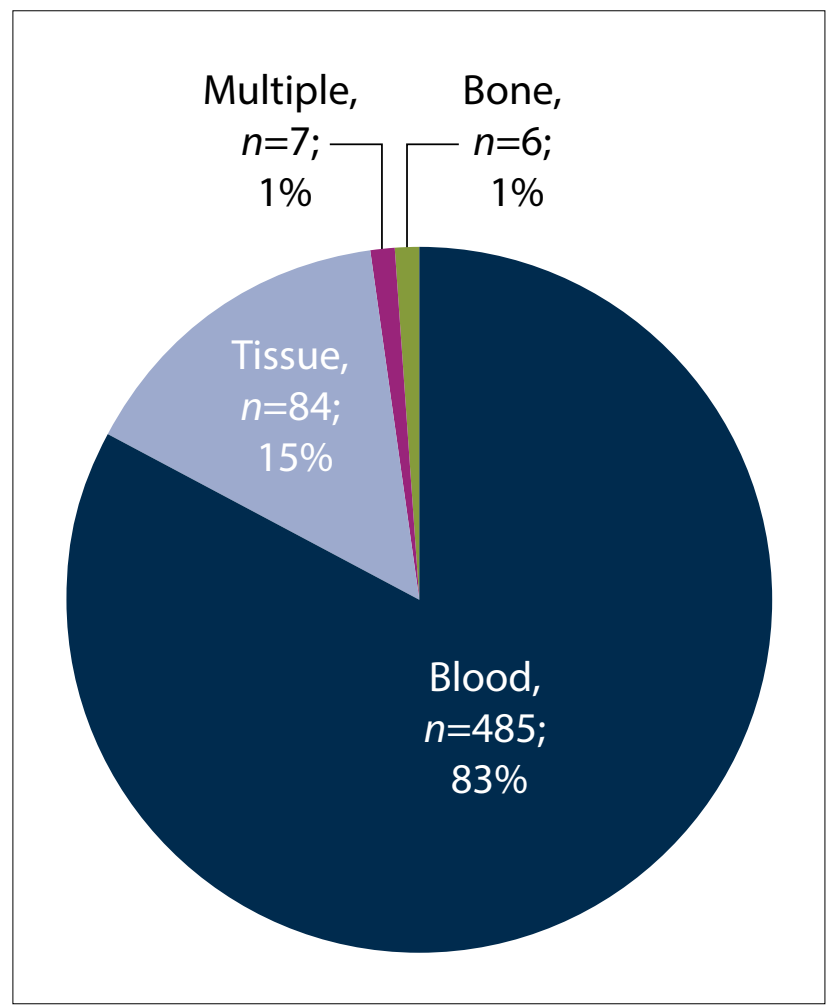

Fig. 3. Type of biological sample obtained at autopsy by the pathologist for DNA analysis. Blood was the most commonly obtained sample type, followed by tissue specimens. In $1 \%$ of cases, bone sections or multiple samples (blood and tissue) were obtained.

having an annual income of less than the minimum wage ${ }^{\left[{ }^{[8]}\right.}$ As such, their next-of-kin may not have the resources to visit the forensic facility for the formal identification process.

Paulozzi et al.$^{[6]}$ identified additional factors, including the prevalence of drug abuse epidemics, and development/accessibility of forensic means of identification. The status of illegal immigrants or undocumented residents can also complicate the process of identification, even when an identity is suspected. SA law and regulations require that identification must be performed by a person in possession of an original identity document; ${ }^{[1]]}$ however, it is suspected that $\sim 40 \%$ of South Africans are not registered at the SA Department of Home Affairs, and therefore do not have an identity document.

Furthermore, identification may also be limited by a lack of antemortem data, which is compounded for poor individuals and illegal immigrants. For these individuals in particular, it is less likely that there are reference data for comparison (e.g. medical and dental records, or fingerprints and DNA profiles on a database). While fingerprints are presumed to be taken from all unidentified individuals at SRM (where possible), it also does not guarantee identification, e.g. if the individual is $<16$ years of age, there may be no reference record at the SA Department of Home Affairs.

Male decedents accounted for $78.7 \%$ of unidentified cases, which is slightly higher than the overall number of males admitted to SRM (75.1\%), with almost half of the individuals being between 20 and 39 years of age (Fig. 2). Similar age distributions were found in studies conducted by Kumar et al. ${ }^{[4]}$ in India, Paulozzi et al. ${ }^{[6]}$ in the USA and Evert et al. ${ }^{[3]}$ in Pretoria, $\mathrm{SA}$, as well as various other international studies. ${ }^{\left[{ }^{6}\right]}$

The rate of non-vehicular injury (e.g. stabbing, shooting, assault and strangulation) cases $(32.3 \% ; n=800)$ was greater than that observed at the Pretoria Medico-Legal Laboratory (23\%). ${ }^{[3]}$ Of particular interest is the large disparity in firearm-related homicides, where the incidence at SRM was $\sim 2.5$-fold greater than that at Pretoria. This may be attributed to the higher rates of gang violence in Cape Town. ${ }^{[22,23]}$ The general make-up of gangs (males between the ages of 20 and 39 years), ${ }^{[22]}$ was also consistent with age and sex demographics of unidentified persons at SRM.

Secondary to unnatural deaths were deaths due to natural causes (18.2\%), which included non-viable fetuses, natural diseases and medical conditions. Non-viable fetus cases and neonatal deaths recorded at SRM (Fig. 2) and internationally are thought to be under-reported owing to the manner in which the fetuses and neonates are 'disposed'; ${ }^{[24]}$ therefore, these statistics are suspected to be unreliable. ${ }^{[25-28]}$ In these cases, identification is exceptionally challenging owing to the overall lack of secondary identifiers, as well as the absence of stored fingerprints and reference DNA profiles on databases (due to the young age of the decedents). While DNA can be useful for identification if a family member comes forward, it is suspected in at least some of these cases that the mother intentionally abandoned the neonate and is unlikely to come forward. Further, due to the infancy of the National Forensic DNA Database (NFDD) of SA, there are not yet enough pre-existing reference profiles on the database, and familial searching has not yet been routinely implemented.

In this study, it was determined that physical inhibitors of visual identification were present in $14.08 \%(n=345)$ of cases owing to decomposition (5.5\%), burns (4.4\%) and skeletonisation (1.6\%). As the next-of-kin can no longer assist with the identification, and fingerprint analysis is often no longer possible, anthropological and DNA assessments are especially important in these cases. The short time elapsing between death declaration and postmortem investigation (median 3 days) suggests that DNA degradation would not be problematic for DNA analyses. ${ }^{[16]}$ However, the time elapsing between the actual death (as opposed to death declaration) and refrigeration has a greater impact on DNA quality. ${ }^{[29,30]}$ In this study, PMI data were only available for 4 cases; therefore, the ability to evaluate the potential usefulness of DNA in these particular cases was limited.

Biological specimens were retained for DNA analysis in $23.6 \%$ of cases that remained unidentified (Fig. 3). This was less than half of that observed by Evert et al. ${ }^{[3]}$ (50\%), but more than that recorded by Kumar et al. ${ }^{[4]}(8 \%)$. In this study, the number of biological specimens retained increased in 2015, which is possibly attributable to the enactment of the South African Criminal Law (Forensic Procedures) Act 37 of 2013, which regulates the NFDD. ${ }^{[31]}$ While it is promising that specimens for DNA human identification were retained, no information regarding the outcome of DNA analyses was available (despite requests for data sharing). This information is important to assess the quality of DNA results obtained and if any individuals had been identified by DNA. Had results been available, the role of DNA within the identification process could have been assessed, which may have led to recommendations regarding the possible improvement of sample collection for DNA analysis or the need to create awareness in family members to provide familial reference samples.

A consistent and striking finding throughout this study was that there was a remarkable lack of record-keeping of information pertaining to identification, e.g. secondary identification features, logging of cases with fingerprints or if forensic odontology had been requested. Kumar et al. ${ }^{[4]}$ found that $65 \%$ of unidentified persons in Chandigarh, India, had identifiable markings on their bodies, such as birthmarks or tattoos, which highlights its potential value. While 
numerous attempts were made to engage with other stakeholders involved in human identification, data pertaining to identification attempts and outcomes were not shared. These results highlight the need for routine documentation and sharing of information among all stakeholders to reduce the burden of identified human remains in SA.

To this end, FPS has initiated a Victim Identification Board (VIB), which is envisaged to comprise representatives from all stakeholders who can meet on a regular basis regarding unidentified cases. The key issue is that a central database is required where features observed at autopsy, and those potentially documented by SAPS, are shared. Important ancillary investigations, such as forensic anthropology and odontology, should also be requested more frequently.

\section{Recommendations}

The underutilisation of DNA, anthropology and odontology suggests that these analyses are undervalued, not financially supported or not applied appropriately to obtain informative data. Furthermore, the current standard operating procedures in place need to be re-examined and updated in such a manner that all stakeholders are aware of their own and each other's responsibilities, where all individuals work together. The identification of cases is a collaborative effort and therefore communication needs to be improved for the deceased to be reunited with their families. It is hoped that the establishment of the abovementioned FPS VIB will assist in improving communication and the process of identification.

Databases and record systems should be better utilised and maintained so that the most up-to-date information is available for reference. ${ }^{[3,6]}$ Through such systems, a standardised record of demographic data, specimens retained and physical identifiers exists and also allows for the tracking of unidentified cases and subsequent removal of the decedent's profile, should they be identified. ${ }^{[32]}$

Furthermore, given the socioeconomic status of many individuals in SA, it might be worthwhile to allocate funds for the transport of family members to the facility for visual identification. While the latter is notoriously inaccurate in neonates or in cases where there are physical inhibitors of identification, the majority of cases that were unidentified at SRM had no inhibitors of identification and were between 20 and 39 years old. Another suggestion would be to adjust standard procedures to allow for FPS/SAPS personnel to travel to the family household and perform identification by means of photography.

Given the infancy of the SA NFDD, it is recommended that efforts need to be made to educate the general public on how to go about reporting a missing family member. It should be explained to the public that reference DNA samples can be submitted by living family members to assist in the identification, should human remains be retrieved.

\section{Conclusions}

The alarmingly high percentage of cases (9.2\%) that remained unidentified is at least 2 -fold higher than that in developing and developed countries. The majority of bodies did not have physical inhibitors of identification, and on average a short time interval between death declaration and postmortem investigation elapsed. These findings suggest that fingerprint and DNA profiling should be used more routinely.

It was determined that the most common profile of unidentified persons at SRM is a male between the ages of 20 and 39 years, most likely of low socioeconomic status. The person probably died from sharp or blunt force trauma, with the body remaining intact, arriving at the forensic facility within 1 day after death, and autopsy being performed on average 3 days after death. In such cases, it is suspected and motivated that both fingerprinting and DNA analysis could be beneficial in the identification process, provided that the individual is thought to be South African.

This retrospective review highlights that unidentified persons are a burden on the SRM facility, and possibly across SA. Furthermore, the large number of individuals remaining unidentified means that there are many families missing a loved one and lacking closure. Efforts to identify these individuals are often perceived as futile and time consuming, especially in developing nations, where resources are limited. There is a need for research to investigate an easier, less expensive and quicker sampling procedure. Moreover, it is important that communication between all involved parties and scientific researchers be improved to ensure that social justice is improved and that the burden of unidentified persons is lessened.

\section{Declaration. None.}

Acknowledgements. The authors would like to acknowledge Dr Vicky Gibbon, Dr Devin Finaughty and Mr Wayne Mitten for their assistance.

Author contributions. KMR performed the study, data analysis and interpretation, and drafted the article. LJM supervised the research and critically reviewed the article. LJH conceptualised the study, supervised the research, assisted with analysis and data interpretation, and critically reviewed and edited the article.

Funding. The authors would like to acknowledge the University of Cape Town Faculty of Health Sciences Research Committee for the publication incentive funding award. The first author would also like to thank the National Research Foundation (NRF South Africa) and The Oppenheimer Memorial Trust for student funding.

Conflicts of interest. None.

1. Cattaneo C, Ritz-Timme S, Schutz HW, et al. Unidentified cadavers and human remains in the EU: An unknown issue. Int J Legal Med 2000;113(3):N2-N3.

2. Cattaneo C, Porta D, de Angelis D, Gibelli D, Poppa P, Grandi M. Unidentified bodies and human remains: An Italian glimpse through a European problem. Forensic Sci Int 2010;195(1-3):167.el-167.e6. https://doi.org/10.1016/j.forsciint.2009.11.008

3. Evert L, Rossouw SH. Unidentified Bodies in Forensic Pathology Practice in South Africa. University of Pretoria: Department of Forensic Medicine, 2011:1-84.

4. Kumar A, Harish D, Singh A. Cause of death in 'John Doe and Jane Doe': A 5 year review. J Clin Diagn Res 2014;8(8):20-23. https://doi.org/10.7860/jicdr/2014/8876.4661

Chattopadhyay S, Shee B, Sukul B. Unidentified bodies in autopsy - a disaster in disguise. Egypt Forensic Sci 2013;3(4):112-115. https://doi.org/10.1016/j.ejfs.2013.05.003

Paulozzi LJ, Cox CS, Williams DD, Nolte KB. John and Jane Doe: The epidemiology of unidentified Paulozzi LJ, Cox CS, Williams DD, Nolte KB. John and Jane Doe: The epidemiology of uniden

Western Cape Government. Forensic pathology services - our facilities. 2018. https://www. Western Cape Government. Forensic pathology services - our facilitis.
westerncape.gov.za/general-publication/our-facilities (accessed 2 May 2018).

westerncape.gov.za/general-publication/our-facilities (accessed 2 May 2018).
. Statistics South Africa. City of Cape Town, South Africa, 2011. http://www.statssa.gov.za/?page_

Statistics South Africa. City of Cape Town, South Africa, 2011. ht

id=993\&id=city-of-cape-town-municipality (accessed 16 April 2018).
9. Saukko P, Knight B. Knight's Forensic Pathology. 3rd ed. London: CRC Press, 2005:1-136,

9. Saukko P, Knight B. Knight's Forensic Pathology. 3rdect
10. South Africa. National Health Act No. 61 of 2003.

10. South Africa. National Health Act No. 61 of 2003.

11. South Africa. National Health Act No. 61 of 2003. Regulations: Rendering of forensic pathology service. Government Gazette No. 41524, 2018. (Published under Government Notice R359.)

12. South Africa. The Inquests Act No. 58 of 1959.

13. Anderson BE. Identifying the dead: Methods utilized by the Pima County (Arizona) office of the medical examiner for undocumented border crossers: 2001- 2006. J Forensic Sci 2008;53(1):8-15 https://doi.org/10.1111/j.1556-4029.2007.00609.x

14. Karu K, Jain AK. Fingerprint classification. Pattern Recognition 1996;29(3):389-404. https://doi org/10.1016/0031-3203(95)00106-9

15. Gill P, Jeffreys AJ, Werrett DJ. Forensic application of DNA 'fingerprints'. Nature 1985;318(6046):577-579. https://doi.org/10.1038/318577a0

16. Reid KM, Martin LJ, Heathfield LJ. Evaluation of DNA profiles obtained from deceased individuals at Salt River Mortuary (South Africa). Austr J Forensic Sci 2019:1-4. https://doi.org/10.1080/00450 618.2019.1569149

17. Sharma P, Gupta N, Saxena S. Experimental studies of forensic odontology to aid in the identification process. J Forensic Dent Sci 2010;2(2):69. https://doi.org/10.4103/0975-1475.81285

18. Pretty IA, Sweet D. A look at forensic dentistry - part 1: The role of teeth in the determination of Pretty IA, Sweet D. A look at forensic dentistry - part 1: The role of teeth in the dete
human identity. Br Dent J 2001;190(7):359-366. https://doi.org/10.1038/s.bdj.4800972a

19. Bidmos MA, Gibbon VE, Strkalj G. Recent advances in sex identification of human skeletal remains in Bidmos MA, Gibbon VE, Strkalj G. Recent advances in sex identification of human skeletal
South Africa. S Afr J Sci 2010;106(11/12):1-6. https://doi.org/10.4102/sajs.v106i1 1/12.238

20. Soler A, Beatrice JS. Expanding the role of forensic anthropology in a humanitarian crisis: An example from the USA-Mexico border. In: Latham KE, O'Daniel AJ, eds. Sociopolitics of Migrant Death and Repatriation. Cham: Springer International Publishing, 2017:115-128. https://doi.org/10.1007/978-3 319-61866-1_9

21. Buikstra JE, Ubelaker DH. Standards for Data Collection from Human Skeletal Remains. Research Series. 44th ed. Arkansas, USA: Archaeological Survey,1994:9. 
22. Kinnes I. Monograph No. 48: From urban street gangs to criminal empires: The changing face of gangs in the Western Cape. Pretoria: Institute for Security Studies, 2000

23. Jensen $S$. The security and development nexus in Cape Town: War on gangs, counterinsurgency and Jensen S. The security and development nexus in Cape Town: War on gangs, counterinsurg
citizenship. Security Dialogue 2010;41(1):77-97. https://doi.org/10.1177/0967010609357038

24. Du Toit C, Martin LJ, Heathfield LJ. Investigation into abandoned neonates admitted to Salt River Forensic Pathology Mortuary, Cape Town. Forensic Sci Int 2018;292:232-241. https://doi.org/10.1016/j. forsciint.2018.09.03

25. Abrahams N, Mathews S, Martin LJ, Lombard C, Nannan N, Jewkes R. Gender differences in homicide of neonates, infants, and children under $5 \mathrm{y}$ in South Africa: Results from the cross-sectional 2009 National Child Homicide study. PLoS Med 2016;13(4):e1002003. https://doi.org/10.1371/journal. pmed. 1002003

26. Mathews S, Martin LJ, Coetzee D, Scott C, Brijmohun Y. Child deaths in South Africa: Lessons from the child death review pilot. S Afr Med J 2016;106(9):851. https://doi.org/10.7196/samj.2016.v106i9.11382

27. Gheorghe A, Banner J, Hansen SH, Stolborg U, Lynnerup N. Abandonment of newborn infants: A Danish forensic medical survey 1997 - 2008. Forensic Sci Med Pathol 2011:7(4):317-321. https./doi. org/10.1007/s12024-011-9253-6
28. Du Toit-Prinsloo L, Pickles C, Smith Z, Jordaan J, Saayman G. The medico-legal investigation of abandoned fetuses and newborns - a review of cases admitted to the Pretoria Medico-Legal Laboratory, South Africa. Int J Legal Med 2015;130(2):569-574. https://doi.org/10.1007/s00414-015-1198-y

29. Hughes-Stamm SR, Ashton KJ, Daal A. Assessment of DNA degradation and the genotyping success of . Hughes-Stamm SR, Ashton KJ, Daal A. Assessment of DNA degradation and the genotyping success of
highly degraded samples. Int J Legal Med 2010;125(3):341-348. https://doi.org/10.1007/s00414-010-0455-3 30. Schlenker A, Grimble K, Azim A, Owen R, Hartman D. Toenails as an alternative source material for 0. Schlenker A, Grimble K, Azim A, Owen R, Hartman D. Toenails as an alternative source material for
the extraction of DNA from decomposed human remains. Forensic Sci Int 2016;258:1-10. https://doi. org/10.1016/j.forsciint.2015.10.02

31. South Africa. Act No. 37 of 2013: Criminal Law (Forensic Procedures) Amendment Act.

32. Hanzlick R, Clark S. The unidentified decedent reporting system: A model national website registry for the unidentified deceased. Am J Forensic Med Pathol 2008;29(2):106-113. https://doi.org/10.1097/ paf.0b013e318174f098

Accepted 15 August 2019. 